\title{
Application of resonant oscillatory systems for the seafloor gas hydrates development
}

\author{
Hennadii Haiko ${ }^{1 *}$, Oleksandr Zhivkov ${ }^{1}$, and Lubov Pyha ${ }^{1}$ \\ ${ }^{1}$ National Technical University of Ukraine "Igor Sikorsky Kyiv Polytechnic Institute”, Department of \\ Geo-Engineering, 37 Peremohy Ave., 03056, Kyiv, Ukraine
}

\begin{abstract}
The prospects for the gas recovery from bottom gas hydrates are studied, and the necessity for the formation of an innovation environment and practical steps for conducting industrial experiments are formulated. The promising methods of shielded development of seafloor gas hydrate deposits are analyzed and the technical problems of their improvement are revealed. The possibilities of using resonant oscillatory systems for the shielded development of bottom gas hydrates are studied, in particular, a Helmholtz flow-excited resonator. The expediency of using high-quality oscillations of the "rotator" type has been substantiated in order to facilitate controlled gas hydrates dissociation over large areas of a gas hydrate field and to counteract the formation of new gas hydrates in the fractures of hydraulic reservoir fracturing. A method has been developed of gas recovery from bottom methane hydrates using a resonator device, which significantly reduces the energy consumption for the gas hydrates dissociation and contributes to the technological processes control.
\end{abstract}

\section{Introduction}

The total methane gas hydrates reserves are almost an order of magnitude greater than the known reserves of conventional natural gas fields, and potentially represent the most powerful source of mineral energy resources at the planet. The prospects for the energy mineral resources development are largely related to the innovative technologies of the methane crystal hydrates extraction in the World Ocean [1-6]. It should be noted that theoretical and experimental studies of gas hydrates and their fields have been conducted for a long time and in many countries of the world [7-11]. For example, the US Congress in 1999 approved the Onshore and Offshore Methane Hydrate Research and Development Act, and in 2013 Japan received the first commercial gas from an offshore gas hydrate field. It is noteworthy that the Ukrainian government adopted the Program for the Black Sea Gas Hydrates Development back in 1993, but a series of economic circumstances and negative external influences excluded the possibility of its realization. Despite the large-scale research projects (mainly geological), industrial gas recovery from methane hydrate fields remains a matter of the future. The causes of this situation should be found in the insufficient development of the technological direction and practical development of seafloor deposits.

\footnotetext{
*Corresponding author: gayko.kpi@meta.ua
} 
It is the authors' opinion that a certain analogy can be drawn with the "shale revolution" in the USA and the problem of seafloor gas hydrates development. Nearly 150 years of shale gas research preceded the "shale revolution" and hardly led the world to a technological solution of the problem. On the contrary, scientific thought for a long time supported the position that the cost of releasing shale gas will always be significantly higher than the development of any conventional gas fields, so the expediency of practical development was postponed for decades. But there were experts who tried to refute this opinion with the help of innovative technological solutions. George Mitchell and his company "Mitchell Energy \& Development" were successful when, in 2001, an industrial competitive technology for shale gas production was developed [12]. There are two important points to note:

1) "Mitchell Energy \& Development" company was neither a pioneer of any hydraulic seam fracturing (the first hydraulic coal seam fracturing was performed in 1947 in Ukraine), nor directional vertical-horizontal drilling of wells (for the first time it was implemented by the American company "Chesapeake Energy" in 1992). However, "Mitchell Energy \& Development" company used and improved these innovative inventions to create new technology.

2) George Mitchell invested his personal $\$ 7$ million into the practical testing of the new method and got a result that has changed the energy "pattern of the world" and brought the United States to the first place in world gas production ("Mitchell Energy \& Development" company, as the owner of a revolutionary technology, was bought by the "Devon Energy" corporation still in 2001 for $\$ 2$ billion).

Thus, it is the development of new technological methods that are based on the innovative achievements of geotechnologies, as well as the attempts for their practical implementation (with simultaneous improvement and adaptation to development conditions) that is the most effective and economically feasible way to solve these problems. Given this, the development of new technological methods of gas recovery from seafloor methane hydrates can contribute to the innovative environment formation that will give a boost to practical pilot-industrial experiments, which will open an energy security alternative direction for many world countries, including Ukraine.

\section{Main part}

This paper expands on the author's concept of shielded development of marine gas hydrate deposits, which provides for covering of seafloor significant areas over a methane hydrate field with a system of flexible gas gathering shells connected to bottom gas pipelines. It also involves dissociation of gas hydrate and release of separated gas from the reservoir under the shielding shells by drilling a vertical-horizontal well into the gas hydrate reservoir, and then the creation of hydraulic fracturing of the reservoir and roof rocks with the formation of fracture system for a gas outlet and supply into the heat carrier well [13, 14]. The method developed is a definite alternative to traditional approaches to the seafloor sediments development. Ingress of methane into the water area, which has always been tried to avoid during the gas hydrate deposits development, becomes the purpose of the main stage in the development of technology, but in a controlled and stable process. The peculiarities of the new approach are the simultaneous gas hydrates dissociation over a large area of the gas hydrate field and the constant release of significant (sufficient for competitive industrial development) methane volumes without the threat of an explosive effect. Significant resource saving is conditioned by the unmanned way of the field operation (all costs and labour resources are concentrated at the preparatory stage of equipment installation), as well as the absence of sea vessels and platforms during the period of methane production. 
Among the disadvantages of the developed methods, it is noted the necessity to inject significant coolant volumes into the gas hydrate reservoir for dissociation of gas over a large area of the reservoir and the possibility of filling the fractures, formed by hydraulic fracturing of the reservoir, with newly formed gas hydrate. This gas hydrate is formed under conditions of a reverse phase transition of released methane and water into an ice-like gas hydrate, which can block the movement of gas through fractures. To solve these technical problems, it is proposed to use the effects of resonant oscillatory systems for the resonant destruction of clogging in gas collectors (created fracture system) and to improve the conditions for gas hydrates dissociation.

Acoustic effects on oil reservoirs and fluid flow collectors to enhance the flow of hydrocarbons into wells are successfully used in oil-and-gas production $[12,15]$. The use of acoustic resonators (in particular, a Helmholtz flow-excited resonator) is one of the most promising directions in the development of this area. Acoustic resonators are capable of sharply (tens and hundreds of times) increasing the amplitudes of stationary oscillations when the external effect oscillation frequency coincides with the values characteristic of the given system [16]. Usually, the purpose of these effects in oil-andgas production is decolmatation (cleansing) of the collector and increasing the fluid mobility in the fractured rock massif. According to the authors, the Helmholtz resonator can be successfully used for a new purpose - for gas hydrates dissociation (the release of methane from the gas hydrate clathrate), since intense wave disturbances of the gas hydrate reservoir lead to an oscillatory process of increasing and decreasing pressure, as well as to increasing the temperature. In addition, they can create conditions for the phase transition of gas hydrate into gas and water, wherein the dissociation rate will depend on the amplitude of oscillations. This opens up new prospects for using the acoustic resonators and requires an analysis of their operation, as well as improvement of constructional design [17].

To model the resonance of the oscillatory processes, the volume of a Helmholtz resonator can be considered, the properties of which are well studied [16]. Usually, air vibrations in the resonator neck are presented in the form of a mechanical analogue "weight on a spring" (Fig. 1a). Taking into account the theory of similarity, in particular, that acoustic (mechanical) and electrical oscillations are described by similar differential equations, oscillations in a Helmholtz resonator can also be represented as oscillations of a series electric circuit (Fig. 1b).

(a)

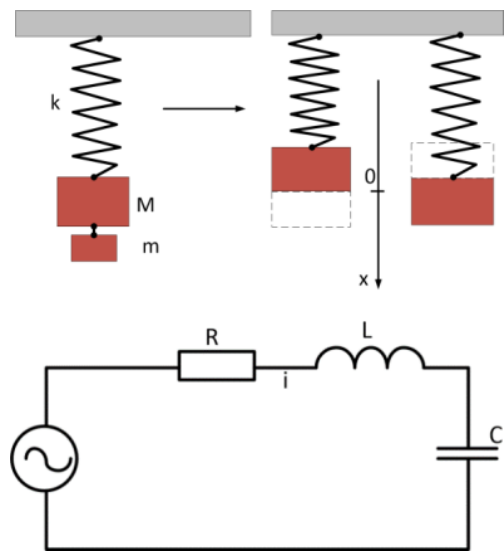

(b)

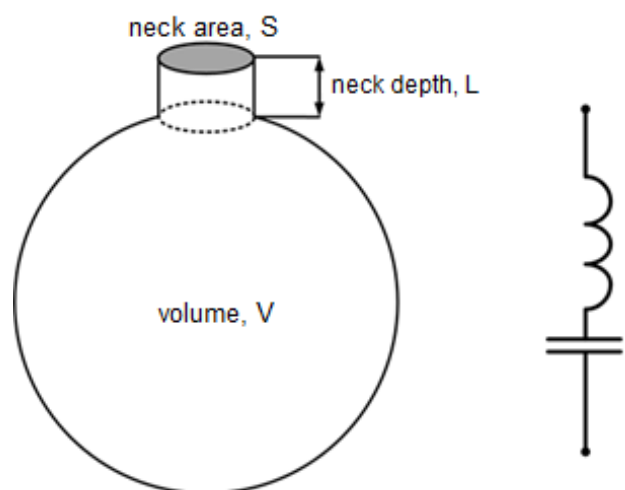

Fig. 1. Analogies of oscillations in the Helmholtz resonator neck. 
Such representations make possible to accurately calculate the resonance Helmholtz resonator frequency, but they do not explain its properties as an elementary cell of acoustic metamaterials. It is noted in the work [18], that, along with "oscillator" type oscillations (antiphase oscillations), the "rotator" type (in-phase) oscillations should be excited in one way or another in the center of the metamaterial. And such oscillations are really excited when the air flow effects on the Helmholtz resonator [19]. In the Helmholtz resonator neck, the so-called "vortices" are excited (Fig. 2), which are nothing more than oscillations of the "rotator" type. In the work [20], the possibility of exciting the Helmholtz resonator by such vortex oscillations is noted, however, any analytical relationships between the frequencies and amplitudes of the Helmholtz resonator natural oscillations and the exciting oscillations of the "rotators" have not been revealed.

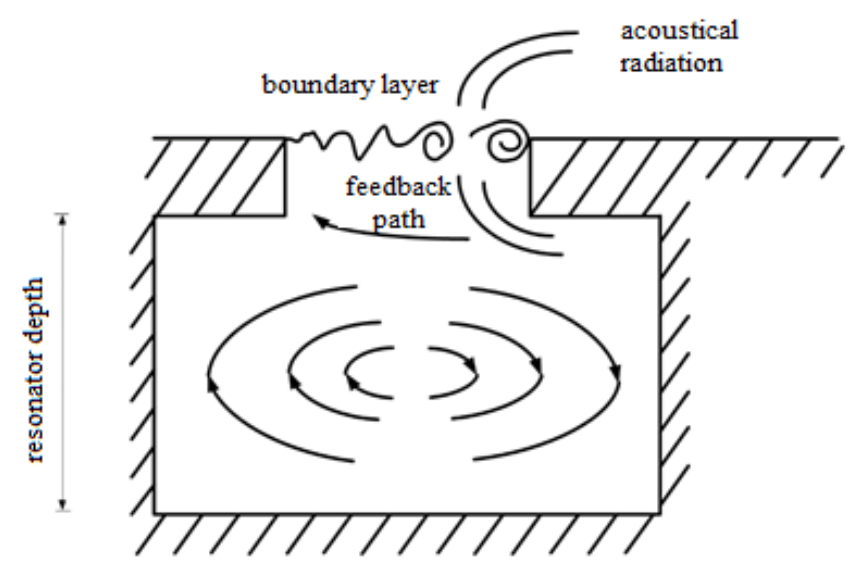

Fig. 2. "Vortices" in the Helmholtz resonator neck, excited by the air flow in the boundary layer.

Meanwhile, similar interactions of two different types of oscillations within the same object, belonging to the class of the "Fano resonance" type of oscillations, are the subject of modern processes study in optics and microwave technology [21,22]. The main characteristic peculiarities of the Fano resonance are an asymmetric resonance curve, the presence of different types of oscillations or wave processes, the presence of two independent energy transmission paths, the presence of the so-called "Fano point", at which complete absorption of the energy transmitted from the input to the output is achieved ("zero" of transmission or "infinite" attenuation).

In this case, as it is noted in the works [22, 23], the equivalent Helmholtz resonator circuit, which is excited by the flow, can be represented not in the form of a series oscillatory resonator (as shown in Fig. 1b), but in the form of a bridge circuit (Fig. 3), in which parallel arms describe oscillations of the "rotator" type (in-phase), and crossed oscillations - the "oscillator" type (antiphase) oscillations.

The essential distinction of the Fano resonance is disturbing the resonances of various types with different quality factor. It is in this case that a "Fano point" arises, at which the signal energy is completely absorbed, and in our case, an intense excitation occurs of the gas-containing volumes of the rock massif, which can effectively "destroy" the colmatation partitions (or, if natural and external oscillations coincide, gas hydrate clathrates). It should be noted that such a destructive resonance vibration of building structures has become widely known under the name "Tacoma Narrows Bridge" (destructing the building structure of a cable-stayed bridge by wind flow). 


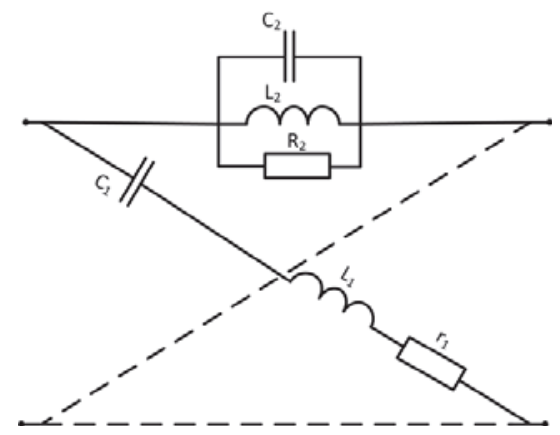

Fig. 3. Bridge circuit for the substitution of the Helmholtz resonator excited by the air flow.

According to the authors, for the effective wave disturbance of oil-and-gas deposits, it is possible to use the generation of high-quality "rotator" type oscillations in the resonator design. It should be noted that the quality factor of oscillations in the volume of excited reservoir can be changed with distance due to losses in the "mechanical partitions". Taking into account the legitimacy of the analogy between mechanical and electrical models, let us use the preliminary theoretical developments [22-24] and consider two resonances, the quality factor of which differs by 50 times, and the excitation level of the "rotator" in relation to the oscillator - by 3 times. Figure 4 a shows the amplitude-frequency characteristics of three oscillations: "green" curve is the resonance of the exciting oscillations (rotator), "red dotted" curve of the Helmholtz resonator natural oscillations, "blue" curve, which has a pronounced Fano resonance asymmetric shape with an almost infinite $(-70 \mathrm{~dB})$ attenuation at the point of relative disturbance $F_{r e l}=-3$ (Fano point), is a characteristic of the total process occurring in the excited volume. It is at this frequency that the most efficient energy absorption, as well as the expected colmatant destruction or the gas hydrate dissociation will occur. It should be noted that if the resonant frequencies of the exciting oscillation ("green" curve) and the natural Helmholtz resonator oscillations (oscillations of the excited volume - "red dotted" curve) coincide, the level of the total oscillations at this frequency can be lower than the level of each of the output oscillations (Fig. 4b).

(a)

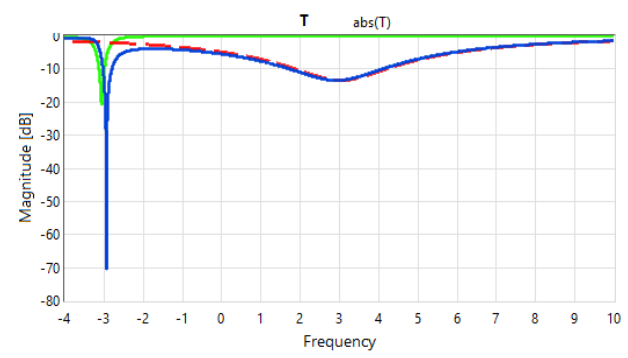

(b)

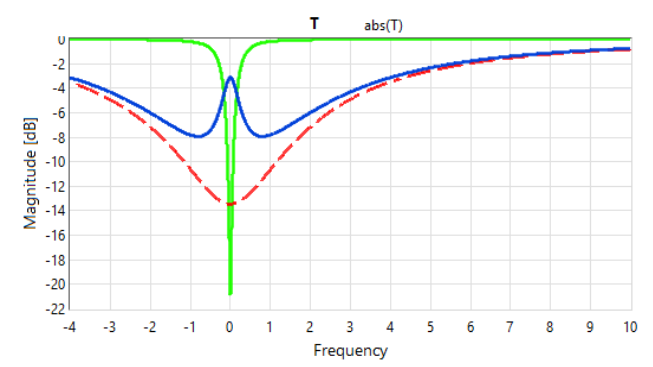

Fig.4. Oscillations in the excited volume with frequency disturbance of natural resonator oscillations and exciting oscillations (a) and the coincidence of these oscillations in frequency (b).

Thus, when designing devices for the resonant destruction of clogging in gas collectors or gas hydrate clathrates, the resonance parameters of which may differ, it is necessary to provide for the possibility to excite the "rotator" type oscillations with amplitude and frequency, which are substantiated in the work [23]. The powerful potential of resonant oscillatory systems should become an integral part of new wave technologies for oil-andgas production. 
In accordance with the specified technical problem, the authors propose to use an acoustic Helmholtz resonator as a device for gas hydrates dissociation [25]. An acoustic Helmholtz resonator is mounted at the end part of the tubing, through which the coolant is fed into the gas hydrate reservoir (Fig. 5). The device converts the kinetic energy of a highvelocity fluid (water) jet into high-intensity oscillatory energy due to resonance, which occurs when the tone frequency of the outlet hole coincides with the natural oscillation frequency of the resonator chamber at the corresponding jet velocity. Pressure oscillations in the fluid jet form a wave field at the well bottom, which propagates through the gas hydrate reservoir and forms an oscillatory system in it. Wave gas hydrates excitations lead to an oscillatory process of increasing and decreasing pressure, creating conditions for the phase transition of gas hydrate into gas and water, while the dissociation rate will be controlled by the amplitude of oscillations.

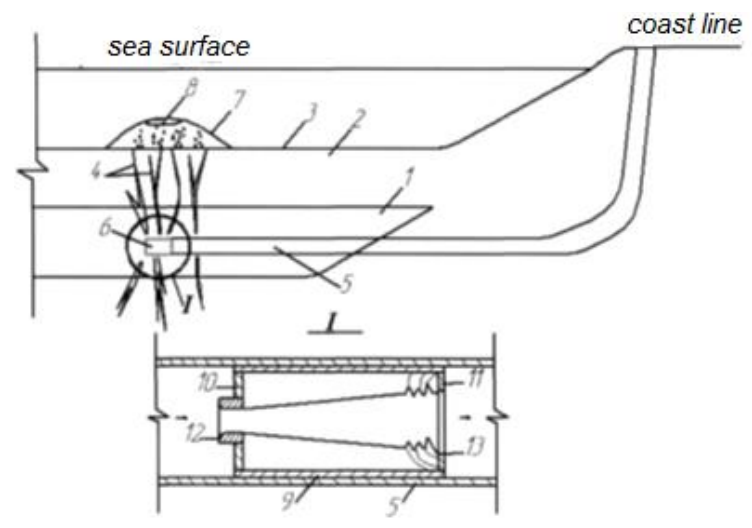

Fig. 5. Scheme of a method for producing methane gas hydrate using a Helmholtz resonator.

Moreover, the temperature of the fluid (coolant) supplied to the gas hydrate reservoir can be significantly reduced (seawater of natural temperature can be supplied), which leads to a significant decrease in energy costs for the gas hydrates dissociation and gas release. The oscillatory processes energy will also prevent undesirable reverse phase transition and the gas hydrates formation in the fractures of gas hydrate reservoir and roof rocks, which are formed by hydraulic fracturing. The wave processes propagation from the injection well bottom over considerable distances will lead to the simultaneous dissociation of gas hydrates in significant volumes, intensive gas release under elastic gas-gathering shields and its withdrawal to consumers.

Fig. 5 shows an acoustic Helmholtz resonator in the methane gas hydrate production scheme. The scheme includes gas hydrate reservoir 1 , covered by roof rocks 2 , which form the seafloor surface 3 and are broken by hydraulic fractures 4 , an injection well with a casing pipe 5, a Helmholtz acoustic resonator 6 rigidly fixed at the end of the casing pipe, elastic gas-gathering shield above the bottom surface 7 with the gas lens 8 . Moreover, the acoustic resonator contains a cylindrical chamber 9 with front 10 and end 11 heads, a supply nozzle 12 and an outlet hole with sharp edges 13 .

The scheme operates as follows. After the gas hydrate reservoir 1 is drilled with a horizontal well, the seafloor surface above the reservoir is shielded with gas-gathering elastic shell 7. An open fracture system 4 is formed by hydraulic fracturing in the gas hydrate reservoir 1 and the roof rocks 2 . Then, the well is cased with an injection pipe 5 at the end of which an acoustic Helmholtz resonator 6 is rigidly fixed and the fluid is fed (for example, sea water at natural temperature). The dimensions of the cylindrical chamber 9 , the supply nozzle 12 and the outlet hole 13 of the resonator 6 correspond to the required 
velocity of fluid supplied to the nozzle 12 to form resonance. Pressure oscillations in the fluid jet, which is supplied to the bottomhole and penetrates into the fractures 4 , create oscillatory excitations in the gas hydrate reservoir 1 and form the necessary conditions for the gas hydrates dissociation (pressure change, temperature increase). The released gas, which through the fracture system 4 penetrates the water over a large area of the seafloor surface 3, accumulating under the elastic gas-gathering shield 7 in the form of gas lenses 8 , is withdrawn by the bottom gas pipeline (not shown) to consumers.

Thus, the effects of resonant oscillatory systems can be used to control gas hydrates dissociation over large areas of a gas hydrate field, counteract the new gas hydrates formation in the reservoir fractures after hydraulic fracturing and ensure a steady release of separated gas into the water area under the gas-gathering shells, as well as further withdrawal through bottom gas pipelines to the consumer.

\section{Conclusions}

The prospects for the energy mineral resources development are largely related to the innovative technologies of the methane crystal hydrates extraction in the World Ocean.

The concept of shielded development of seafloor gas hydrate deposits, which can be improved through the use of acoustic resonators (in particular, a Helmholtz flow-excited resonator), is one of the most promising directions in the development of this area. These oscillatory systems are capable of sharply (tens and hundreds of times) increasing the amplitudes of stationary oscillations when the external effect oscillation frequency coincides with the values characteristic of the given system. This opens up new prospects for the use of acoustic resonators in the methods of producing methane from gas hydrate deposits.

A method has been developed using a Helmholtz flow-excited resonator, which significantly reduces energy consumption for the gas hydrates dissociation and provides simultaneous gas release under gas-gathering shells over a large area of the gas hydrate field, where the oscillatory process propagates. In addition, the rate of gas release can be controlled by the amplitude of oscillations.

The authors express their gratitude to Acad. M. Ilchenko (Igor Sikorsky Kyiv Polytechnic Institute) for the scientific analysis of the "rotator" type high-quality oscillations of acoustic resonators, which opens up new opportunities for the technological application of oscillatory systems.

\section{References}

1. Shnyukov, Ye.F., \& Ziborov, A.P. (2004). The mineral wealth of the Black Sea. Kyiv, Ukraine: Department of Marine Geology and Sedimentary Ore-Formation under the National Academy of Sciences of Ukraine.

2. Bondarenko, V., Ganushevych, K., Sai, K., \& Tyshchenko, A. (2011). Development of gas hydrates in the Black Sea. Technical and Geoinformational Systems in Mining: School of Underground Mining 2011, 55-60. https://doi.org/10.1201/b11586-12

3. Sai, K., Malanchuk, Z., Petlovanyi, M., Saik, P., \& Lozynskyi, V. (2019). Research of Thermodynamic Conditions for Gas Hydrates Formation from Methane in the Coal Mines. Solid State Phenomena, (291), 155-172. https://doi.org/10.4028/www.scientific.net/SSP.291.155

4. Pivnyak, G., Bondarenko, V., Kovalevs'ka, I., \& Illiashov, M. (2012). Geomechanical processes during underground mining. London, United Kingdom: CRC Press, Taylor \& Francis Group.

5. Bondarenko, V., Kovalevs'ka, I., \& Ganushevych, K. (2014). Progressive technologies of coal, coalbed methane, and ores mining. London, United Kingdom: CRC Press, Taylor \& Francis Group. https://doi.org/10.1201/b17547 
6. Pivnyak, G., Bondarenko, V., \& Kovalevska, I. (2015). New developments in mining engineering 2015. London, United Kingdom: CRC Press, Taylor \& Francis Group. https://doi.org/10.1201/b19901

7. Dreus, A.Yu., Bondarenko, V.I., Biletskyi, V.S., \& Lysenko, R.S. (2020). Mathematical simulation of heat and mass exchange processes during dissociation of gas hydrates in a porous medium. Naukovyi Visnyk Natsionalnoho Hirnychoho Universytetu, 5(179), https://doi.org/10.33271/nvngu/2020-5/033

8. Ovchynnikov, M., Ganushevych, K., \& Sai, K. (2013). Methodology of gas hydrates formation from gaseous mixtures of various compositions. Annual Scientific-Technical Collection - Mining of Mineral Deposits, 203-205. https://doi.org/10.1201/b16354-37

9. Bondarenko, V., Svietkina, O., \& Sai, K. (2017). Study of the formation mechanism of gas hydrates of methane in the presence of surface-active substances. Eastern-European Journal of Enterprise Technologies, 5(6 (89)), 48-55. https://doi.org/10.15587/1729-4061.2017.112313

10. Maksymova, E., Ovchynnikov, M., Lysenko, R., \& Kostrytska, S. (2018). Physical and chemical methods of methane utilization in Ukrainian coal mines. Solid State Phenomena, (277), 147-156. https://doi.org/10.4028/www.scientific.net/SSP.277.147

11. Bondarenko V., Kovalevska I., Astafiev D., Malova O. (2018). Examination of phase transition of mine methane to gas hydrates and their sudden failure - Percy Bridgman's effect. Solid State Phenomena, (277), 137-146. https://doi.org/10.4028/www.scientific.net/SSP.277.137

12. Biletsky, V.S., Haiko, H.I., \& Orlovsky, V.M. (2019). Istoriya ta perspektyvy naftohazovydobuvannya. Lviv, Ukraina: Novyy Svit.

13. Haiko, H., \& Pyha, L. (2017). Shielded development of bottom gas hydrates. Mining of Mineral Deposits, 11(3), 117-123. https://doi.org/10.15407/mining11.03.117

14. Haiko, H., Ogorodnyk, Y., Pyha, L., \& Durove, J. (2018). Shielded development of marine bottom gas hydrates by fracking a layer. Solid State Phenomena, (277) 27-35. https://doi.org/10.4028/www.scientific.net/ssp.277.27

15. Kuznetsov, O.L., Simkin, E.M., \& Chilingar Dzh. (2001). Fizicheskiye osnovy vibratsionnogo $i$ akusticheskogo vozdeystviya na neftegazovyye plasty. Moskva, Rossiya: Mir.

16. Mechel, F.P. (2008). Formulas of acoustics editors. London, United Kingdom: Springer.

17. Hayko, H.I., Zhyvkov, O.P., Kamaral,i R.V., \& Pyha, L.M. (2019). Rezonator hel'mhol'tsa i rezonans Fano v protsesakh naftohazovydobuvannya. II Mizhnarodna Naukovo-Tekhnichna Konferentsiya "Problemy Heoinzheneriyi ta Pidzemnoyi Urbanistyky". Kyiv, Ukraina.

18. Ilchenko, M.E., \& Zhivkov, A.P. (2017). Areas of degeneration oscillations in metamaterial cells. International Conference on Information and Telecommunication Technologies and Radio Electronics (UkrMiCo).

19. Ghanadi, F., Arjomandi, M., Cassolato, B., \& Zander, A. (2014). Interaction of a flow-excited Helmholz resonator with a grazing turbulent boundary layer. Experimental Thermal and Fluid Science, (58) 80-92. https://doi.org/10.1016/j.expthermflusci.2014.06.016

20. Pimshteyn, V.G. (2010). Aeroakusticheskiye vzaimodeystviya v turbulentnykh struyakh. Moskva, Rossiya: FIZMATLIT.

21. Kamenetskii, E., Sadreev, A., \& Miroshnichenko, A. (2018). Fano resonances in optics and microwaves. London, United Kingdom: Springer.

22. Zhivkov, A.P., Shevtsov, K.O., \& Kamarali, R.V. (2019). Fano resonance and metamaterial cells equivalent circuits. International Conference on Information and Telecommunication Technologies and Radio Electronics (UkrMiCo).

23. Ilchenko, M., Uryvsky, L., \& Globa, L. (2019). Advances in information and communication technologies. London, United Kingdom: Springer.

24. Dychkovskyi, R., Vladyko, O., Maltsev, D., Cabana, E.C. (2018). Some aspects of the compatibility of mineral mining technologies. Rudarsko-Geološko-Naftni Zbornik, 33(4), 73-82. https://doi.org/10.17794/rgn.2018.4.7

25. Hayko, H.I., Zhyvkov, O.P., \& Pyha, L.M. (2019). Application of acoustic helmholtz resonator for dissociation of gas hydrates. Patent UA \#137077. Kyiv, Ukraine. 